\title{
CRIATIVIDADE LEXICAL NA LITERATURA INFANTIL: OS NEOLOGISMOS EM MARCELO, MARMELO, MARTELO
}

\author{
Everton Lourenço da Silva Maximo \\ Mestre em Linguística pela Universidade Federal do Rio de Janeiro (UFRJ) \\ Professor da Faculdade Machado de Assis (FAMA) \\ everton.lourenco.maximo@gmail.com \\ Beatriz Borges Bareli Gomes \\ Graduada em Letras (Português/Inglês) pela Faculdade Machado de Assis (FAMA) \\ beatrizbareli.rj@gmail.com
}

\section{RESUMO}

No presente trabalho abordaremos o fato de a linguagem literária ser uma importante fonte para os estudos linguísticos. Para tanto, analisaremos os neologismos contidos na obra Marcelo, marmelo, martelo de Ruth Rocha (1976), em que a autora cria novas palavras para as já existentes através do olhar de uma criança, o personagem Marcelo, que questiona a arbitrariedade do signos linguísticos e propõe mudanças para os mesmos, de forma que os novos signos não Ihe pareçam arbitrários. Sendo assim, veremos como a língua provê recursos para a criação neológica, buscando compreender como a autora lança mão desses recursos em prol de sua expressão literária.

Palavras-chave: neologia, signo linguístico, arbitrariedade, literatura infantil.

\begin{abstract}
In the present work we will address the fact that literary language is an important source for linguistic studies. To do so, we will analyze the neologisms contained in the book Marcelo, marmelo, martelo by Ruth Rocha (1976), in which the author creates new words for those already existing from a point of view of a child, the character Marcelo, who questions the arbitrariness of the linguistic signs and proposes changes to them, so that the new signs do not seem arbitrary. Thus, we will see how the language provides resources for the neological creation, seeking to understand how the author uses these resources for her literary expression.
\end{abstract}

Keywords: neology, linguistic sign, arbitrariness, children's literature. 


\section{Introdução}

A linguagem literária tem suas especificidades e está "a serviço da criação estética, utilizando sistematicamente recursos e convenções próprias de objetivo artístico" (CAMARA JR., 2004, p.162). Assim, na busca pela elaboração da linguagem, os escritores lançam mão das potencialidades da língua com finalidades distintas daquelas que em geral têm os falantes em situações comunicativas cotidianas.

Dessa forma, na literatura vemos as estruturas linguísticas sendo levadas ao limite, fugindo muitas vezes da norma, enquanto são exploradas as mais diversas possibilidades do sistema linguístico. Por essa razão, Campos (2012, p. 1) diz que "o texto literário apresenta-se, pois, como corpus ideal para que se vivencie a língua materna em todas as suas possibilidades, estabelecendo uma relação de empatia que redunda em conhecimento, ludicidade e prazer".

Uma das muitas formas através das quais a excepcionalidade do discurso literário se faz aparente é a criação neológica. Isso ocorre porque muitos escritores, no trabalho com a linguagem, acabam por perceber os diversos modos de criação de vocábulos que a língua oferece. Um caso bastante conhecido em nossa literatura é o de Guimarães Rosa, que empregou em sua obra um grande número de neologismos com diferentes processos de criação, tais como: brincação (derivação sufixal), receder (derivação prefixal), arredondinhar (derivação parassintética), estar-estâncias (justaposição) e adormorrer (aglutinação).

Na literatura infantil é também bastante recorrente o emprego de formações neológicas. Para Silva (2017), tal recorrência está relacionada à fala da criança que, por ainda não dominar completamente a língua, acaba por criar novas palavras ao estruturá- 
las de modo análogo ao de outras palavras semelhantes. Assim, Silva (2017) relaciona formações típicas da fala infantil - como a conjugação de verbos irregulares a partir do paradigma dos verbos regulares (fazi em analogia a comi) - com neologismos, que também seriam criados por mutação analógica. Desse modo, em exemplos como "bruxaria fadal" e "humilhação sapal" de Orthof (apud SILVA, 2017, p. 197-198), os novos vocábulos teriam sido criados em analogia a adjetivos terminados em -al, como nos casos de "amor maternal", "rosto angelical" e "calor infernal". Camara Jr (2004, p. 51) chama esse fenômeno de criação analógica.

Ora, para trabalhar dessa forma a linguagem, com vistas a explorar a língua de modo a produzir expressividade, o escritores têm de usar de forma consciente o seu conhecimento linguístico, normalmente inconsciente. Sendo assim, o estudo de neologismos através da literatura infantil se justifica como um empreendimento com grande potencial para deslindar os meandros da competência lexical.

No presente trabalho analisaremos os neologismos contidos na obra Marcelo, marmelo, martelo, de Ruth Rocha (1976), em que a autora cria novas palavras para as já existentes através do olhar de uma criança, o personagem Marcelo, que questiona alguns signos linguísticos e propõe mudanças para os mesmos, de forma que os novos signos não Ihe pareçam arbitrários. Sendo assim, buscaremos compreender como a autora se vale dos recursos providos pela língua em prol de sua expressão literária.

\section{O fenômeno da neologia}

O termo neologia é normalmente definido como o processo de criação de unidades lexicais e "traduz a capacidade natural de renovação do léxico de uma língua 
pela criação e incorporação de unidades novas" (CORREIA; ALMEIDA, 2012, p. 17). De modo geral, a literatura sobre o assunto tem distinguido entre dois tipos de neologia em relação à razão de sua criação: a neologia denominativa e a neologia estilística (ou conotativa).

Segundo Guilbert (1973), a neologia denominativa resulta da necessidade de se atribuírem nomes àquilo que é inventado, uma vez que um objeto (ou um conceito) inédito não possui nome no léxico da língua. Os neologismos resultantes desse processo tendem a entrar no sistema linguístico, seguindo a penetração social do objeto (ou do conceito) que nomeiam.

Por sua vez, a neologia estilística (ou conotativa) "está baseada na busca da expressividade para traduzir pensamentos velhos de maneira nova, ou para nomear modos de pensar e de sentir inéditos"ii (GUILBERT, 1973, p. 25). Esse tipo de neologia é a que mais interessa quando se estuda o fenômeno neológico em obras literárias, uma vez que os vocábulos criados, em geral, não estão sendo usado para nomear algo novo, mas para lançar um novo olhar sobre algo antigo. Por seu caráter mais subjetivo, os neologismos resultantes desse processo tendem a ter uma existência efêmera, ficando restritos ao nível do discurso, sem se perpetuar no sistema linguístico (CORREIA; ALMEIDA, 2012, p. 18). Sobre isso comenta Camara Jr. (1978, p. 63):

Criações destas não vêm a ser, propriamente, um enriquecimento do vocabulário (...) valem por seu efeito de momento, como uma comparação ou uma metáfora, e, como elas, não visam a radicar-se na língua, senão a executar uma tarefa expressiva no discurso.

\subsection{0 conceito de neologismo}


O conceito de neologismo tem gerado certa controvérsia na literatura sobre o tema, uma vez que os critérios propostos para a delimitação do que é neologismo são variados. Uma proposta bastante conhecida é a de Guilbert (1975) que apresenta o conceito de sentimento de novidade, que consiste no reconhecimento por parte do falante da inovação lexical. A esse respeito, Alves (2007, p. 83-84) comenta:

Ao criar um neologismo, o emissor tem, muitas vezes, plena consciência de que está inovando, gerando novas unidades lexicais (...). Essa sensação de neologia traduz-se graficamente por processos visuais como aspas, maiúsculas e itálico (...).

Do ponto de vista da recepção, o mesmo ocorre, isto é, diante de uma palavra criada, o ouvinte/leitor também é tomado por uma sensação de novidade, reconhecendo um neologismo. Assim tanto emissor quanto receptor estão envolvidos na inovação lexical, como aponta Guilbert (1973, p. 13): “É, portanto, o sujeito falante que cria o neologismo, mas o faz enquanto membro de uma comunidade com a intenção, explícita ou não, de enriquecer a comunicação. Ao mesmo tempo, o interlocutor envolve-se na criação, uma vez que é o destinatário".

Esse critério de natureza psicológica é, em certa medida, um tanto frouxo, uma vez que o léxico muda de falante para falante, dependendo de vários fatores, como o local em que vive, seus interesses, o nível de cultura, o grupo social a que pertence, entre outros. Assim, o falante pode ter um falso sentimento de neologia, já que sempre haverá a possibilidade de estar diante de uma palavra desconhecida, mas já existente na língua.

Sendo assim, em geral, usam-se critérios mais objetivos para a definição de neologismo. Uma alternativa bastante utilizada é o critério lexicográfico, isto é, considerar como neologismos apenas as palavras não encontradas em dicionários. 
Embora os dicionários demorem a absorver inovações lexicais e utilizem critérios nem sempre muito claros na seleção das inovações incorporadas, podemos considerar que uma palavra dicionarizada deixou de ser um neologismo e passou a integrar o vocabulário estabelecido de uma língua.

A despeito dessa dificuldade de caracterização, ficaremos aqui com a definição de neologismo apresentada por Alain Rey (apud CORREIA; ALMEIDA, 2012, p. 23):

\begin{abstract}
Neologismo é uma unidade lexical cuja forma significante ou cuja relação significado-significante, caracterizada por um funcionamento efetivo num determinado modelo de comunicação, não se tinha realizado no estágio imediatamente anterior do código da língua.
\end{abstract}

Os neologismos são tradicionalmente classificados, pelo tipo de novidade que apresentam, em dois grupos: formais e semânticos. Os neologismos formais ocorrem quando a sua forma significante é nova. Isso pode ocorrer através de diversos processos, como sufixação, prefixação e composição. Por sua vez, nos neologismos semânticos o significante já existe, porém é usado para designar outros conceitos além dos atuais, isto é, há atribuição de um novo significado ao significante.

\title{
1.2 Neologismos e a arbitrariedade do signo
}

De acordo com Saussure (2008), o sistema linguístico é constituído por signos, que são unidades formadas por duas partes: o significado (ou conceito) e o significante (ou imagem acústica). Para o linguista, "esses dois elementos estão intimamente unidos e um reclama o outro" (SAUSSURE, 2008, p.80). Uma propriedade fundamental do signo 
linguístico é a arbitrariedade, ou seja, a inexistência de uma relação motivada entre significado e significante. Assim, Saussure (2008, p. 81-82) afirma:

A ideia de mar não está ligada por relação alguma interior à sequência de sons m-a-r que lhe serve de significante; poderia ser representada igualmente bem por outra sequência, não importa qual; como prova, temos as diferenças entre as línguas e a própria existência de línguas diferentes.

Essa arbitrariedade, contudo, pode ocorrer em níveis diferentes, como mostra Costa (2011, p. 122): "Saussure reconhece que a arbitrariedade é limitada por associações e motivações relativas: assim, 'vinte' é imotivado, mas 'dezenove' não é no mesmo grau, porque evoca os termos dos quais se compõe, 'dez' e 'nove'”. Desse modo, Saussure classifica a arbitrariedade em dois tipos: absoluta e relativa. Na arbitrariedade absoluta não é necessário que haja a mínima motivação para escolha de um significante, já na arbitrariedade relativa encontra-se algum fundamento para escolha do mesmo, como no exemplo das palavras derivadas.

Podemos perceber a distinção entre arbitrariedade absoluta e arbitrariedade relativa quando comparamos palavras complexas com palavras monomorfêmicas. Assim, a palavra feliz é absolutamente arbitrária, uma vez que não há relação alguma entre o seu significado e sua forma. Por usa vez, a palavra infeliz apresenta alguma relação entre forma e significado, uma vez que o significado do todo é o resultado da soma do significado das de partes. Contudo, quando analisamos os elementos que formam a palavra, vemos que a relação entre forma e significado é arbitrária. Portanto, dizemos que na palavra infeliz a arbitrariedade é relativa. 
Nos casos de neologismos literários são mais comuns que sejam empregadas palavras relativamente arbitrárias. Ou seja, a partir de uma base arbitrária, cujo significado o leitor conhece, o escritor inova criando palavras cujo significado pode ser depreendido pelo significado de suas partes.

\subsection{0 fenômeno do bloqueio}

Quando falamos em neologia, é importante observar um fenômeno que em geral traz uma restrição à criação de novas palavras. Trata-se do fenômeno do bloqueio, postulado por Aronoff (1976, p.43) nos seguintes termos: "a não ocorrência de uma forma devido à simples existência de outra".

Por conta desse fenômeno, formas regulares e produtivas não ocorrem por já existir uma palavra concorrente. É muito comum que o bloqueio ocorra quando existem afixos com a mesma função, como os sufixos formadores de substantivo -mento e -ção. Assim, as formas *dedetizamento e *musculamento poderiam ser empregadas na língua, mas são bloqueadas pela existência das palavras dedetização e musculação. O mesmo ocorre com as palavras *trancação e *sofreção, bloqueadas por trancamento e sofrimento. Sendo assim, podemos dizer que o bloqueio, em certa medida, cerceia a criatividade lexical dos falantes, refreando a criação de novos itens lexicais.

Convém observar que nem sempre formas concorrentes deixam de existir por conta do bloqueio. Isso ocorre, sobretudo, nos casos em que há especialização no sentido de uma das palavras, como no caso dos vocábulos recepção e recebimento, ambos derivados do verbo receber. 
No caso dos neologismos literários, não é incomum que o bloqueio seja burlado e formas concorrentes de outras que já existem sejam criadas. Isso ocorre porque na literatura, como já vimos, é empregada a neologia estilística, de modo que a criação de palavras não visa a simplesmente dar um nome alternativo às coisas, mas tem finalidade expressiva. Por isso, Guilbert (1975, p. 41), falando de neologia estilística diz que:

Esta forma de criação, a rigor chamada de poética, pela qual são produzidos um novo material linguístico e um significado diferente daquele mais difundido, está relacionada à profunda originalidade do indivíduo falante, à sua faculdade de criação verbal, à sua liberdade de expressão, fora dos modelos recebidos ou contra os modelos recebidos. Ela é própria daqueles que têm algo a dizer, que se sentem bem, e que querem dizer com suas palavras, seus arranjos de palavras, ela é própria dos escritores.

\section{Os neologismos em Marcelo, Marmelo e martelo}

No livro Marcelo, marmelo, martelo (ROCHA, 1976) o personagem principal, o menino Marcelo, questiona o nome das coisas a sua volta. Ele não consegue compreender o porquê da escolha de certas palavras sem nenhum motivo considerado justo por ele. Assim, a obra "tematiza a arbitrariedade do signo linguístico, vivenciada comicamente pelo protagonista, um menino entretido em explorar a elasticidade sonora e semântica das palavras" (LAJOLO; ZILBERMAN, 1987, p. 155).

E Marcelo continuou pensando: "Pois é, está tudo errado! Bola é bola porque é redonda. Mas bolo nem sempre é redondo. E por que será que bola não é a mulher do bolo? E bule? E bala? Eu acho que as coisas deviam ter nome mais apropriado. Cadeira, por exemplo. Devia se chamar sentador, não cadeira, que não quer dizer nada. E travesseiro? 
Devia se chamar cabeceiro, lógico! Também, agora só vou falar assim." (ROCHA, 1976, p. 13).

Para resolver seus questionamentos, Marcelo decide inventar novas palavras a partir das já existentes, pois considera que assim elas apresentam mais sentido. Ou seja, o menino tenta criar signos que não lhe pareçam arbitrários. Para isso, ele usa como padrão formações regulares, seguindo os exemplos de outras palavras semelhantes.

No caso da palavra cabeceiro, usada para designar o travesseiro, ao substantivo cabeça é acrescentado o sufixo -eiro, dando origem a um novo vocábulo que nomeia o objeto cuja utilidade tem a ver com a palavra original. O mesmo acontece com sentador, que substitui a palavra cadeira, considerada arbitrária. Marcelo forma o neologismo com o acréscimo do sufixo -dor ao verbo sentar, formando uma palavra que designa o objeto que se usa para sentar.

Podemos, portanto, observar que Marcelo procura, na verdade, evitar a arbitrariedade e crê ter atingido seu objetivo, sem perceber que as palavras por ele inventadas ainda são arbitrárias, embora sua arbitrariedade não seja absoluta, mas relativa. Tal crença pode ser atribuída ao modo como os neologismos são criados, isto é, através de processos que geram composicionalidade semântica, principalmente a derivação. Sendo assim, nos exemplos de cabeceiro e sentador, o personagem acredita existir um real motivo para escolha desses significantes, embora não perceba que a arbitrariedade do significado das partes que os compõem torna arbitrária a forma final, ainda que se trate de uma arbitrariedade relativa.

Outro aspecto a se observar é que, apesar de o menino achar que pode encontrar nomes mais apropriados para as coisas, ele acaba ignorando uma propriedade fundamental do signo linguístico, o fato de ele ser convencional. Para Saussure, a escolha 
do significante para um determinado significado é feita por uma convenção entre os falantes da língua. Uma palavra utilizada para designar algo é aceita por toda comunidade linguística, pois a língua é "uma instituição social resultante do costume e da tradição, portanto de um contrato tácito entre os homens" (DUBOIS et al., 2006, p. 253). Por isso, não é possível que uma única pessoa dessa comunidade tente mudar um determinado signo, pois esse foi instituído no compartilhamento social.

Sendo assim, a pretensão de Marcelo de dar novos nomes às coisas, ou seja, de atribuir significantes novos aos significados desrespeita a convencionalidade, uma vez que não cabe a um único falante modificar o signo linguísticoiii. Essa ideia é expressa pelo pai em seu alerta para o filho: "Marcelo, todas as coisas têm um nome. E todo mundo tem que chamar pelo mesmo nome porque, senão, ninguém se entende..." (ROCHA, 1976, p. 15). Como o pai havia avisado, o discurso de Marcelo se torna incompreensível:

Marcelo entrou em casa correndo:

- Papai, papai, embrasou a moradeira do Latildo!

- O quê, menino? Não estou entendendo nada!

- A moradeira, papai, embrasou...

— Eu não sei o que é isso, Marcelo. Fala direito!

- Embrasou tudo, papai, está uma branqueira danada!

Seu João percebia a aflição do filho, mas não entendia nada... (ROCHA, 1976, p. 20).

O uso dos neologismos por parte de Marcelo gerando a incompreensão do pai no momento em que há um incêndio na casa de cachorro contribui para a construção do clímax da narrativa, quando o conflito estabelecido pelo uso inovador do menino tem como consequência a impossibilidade de comunicar o que se passa e a consequente destruição da casa de cachorro. Sobre isso, Lajolo \& Zilberman (1987, p. 155) comentam: 
Na medida em que os novos nomes que ele atribui às coisas fazem-no viver situações problemáticas, a história incorpora a ambiguidade do compromisso entre, de um lado, os usos sociais da linguagem e, de outro, os limites que tal uso impõe às interferências do falante no sistema linguístico.

Além da questão da convencionalidade do signo, é preciso notar que as criações de Marcelo também burlam o fenômeno do bloqueio, de que tratamos anteriormente. Ou seja, embora Marcelo não despreze os mecanismos de formação de palavras, suas criações neológicas concorrem com formas já existentes na língua. Assim, as palavras cabeceiro e sentador, embora sejam perfeitamente possíveis, fazendo parte do léxico virtual da língua, são bloqueadas pela existência de travesseiro e cadeira. Desse modo, o fenômeno de bloqueio normalmente coibiria todas as invenções do menino.

Esse fato potencializa a sensação de neologia e faz com que as criações do protagonista causem um maior estranhamento não só para os outros personagens, como também para o leitor, que é levado a refletir sobre a justeza dos nomes que aprendeu por convenção, uma vez que lhe são apresentados vocábulos que parecem menos arbitrários. Dessa forma, o leitor se vê captado pelo conflito central da trama entre a convencionalidade e arbitrariedade do signo linguístico.

O desfecho da trama é apaziguador, com os pais usando as inovações do filho e, até mesmo, empregando seus próprios neologismos.

E o pai do Marcelo falou:

- Não fique triste, meu filho. A gente faz uma moradeira nova pro Latildo.

E a mãe do Marcelo disse:

- É sim! Toda branquinha, com a entradeira na frente e um cobridor bem vermelhinho... (ROCHA, 1976, p. 22). 
Contudo, nesta narrativa a criatividade lexical é uma característica da linguagem infantil. Por isso, os pais não têm a mesma desenvoltura do menino, e há uma presunção de estranhamento por parte dos outros integrantes da comunidade linguística.

E agora, naquela família, todo mundo se entende muito bem.

O pai e a mãe do Marcelo não aprenderam a falar como ele, mas fazem força pra entender o que ele fala.

E nem estão se incomodando com o que as visitas pensam... (ROCHA, 1976, p. 23).

A partir do exposto, vemos como a exploração linguística em Marcelo, marmelo e martelo leva os personagens a desrespeitar certas propriedades da língua, gerando com esse uso inusitado dos recursos linguísticos um efeito estilístico que causa um divertido estranhamento no leitor, mobilizando seu imaginário e fazendo com que ele reflita sobre a própria língua com a mesma ludicidade do menino Marcelo.

\subsection{Análise das formações neológicas}

Em Marcelo, marmelo, martelo os neologismos são criados, em quase sua totalidade, por derivação sufixal. Em todas as ocorrências desse tipo de formação, o significado das novas palavras é formado composicionalmente, dando origem a vocábulos cuja arbitrariedade é relativa. Nesta seção, analisaremos cada uma das inovações lexicais presentes no livro.

Com o uso do sufixo -eiro(a), existem sete formações, das quais analisaremos, por ora, apenas seis: cabeceiro (travesseiro), entradeira (porta), carregadeira (carroça), puxadeiro (burro), branqueira (fumaceira) e moradeira (casa de cachorro). O uso desse 
sufixo para as criações neológicas nesta obra compreende três noções: objeto/instrumento, agente e acúmulo/grande quantidade.

A noção de objeto/instrumento está presente nos casos de cabeceiro, entradeira, carregadeira e moradeira. Como vimos, em cabeceiro, o sufixo -eiro é acrescentado à base nominal cabeça, um processo bastante comum, conforme atestam variados exemplos, tais como: cinzeiro, lixeira, saleiro, açucareiro e papeleira. Nos casos de entradeira, carregadeira e moradeira, o sufixo é preso a bases flexionadas no particípio: entrad(o), carregad(o), morad(o). Esse é o mesmo processo encontrado nos seguintes casos: furadeira, mamadeira, assadeira, abotoadeira e espreguiçadeira.

A noção de agente está presente na palavra puxadeiro, que Marcelo cria para designar o burro que puxa a carroça. Aqui, o sufixo também está ligado a uma base flexionada no particípio, numa formação semelhante à das seguintes palavras: lavadeira, passadeira, arrumadeira e benzedeira.

Por sua vez, a noção de acúmulo/grande quantidade está contida na palavra branqueira, utilizada para expressar grande quantidade de fumaça. Para essa criação, Marcelo se baseia na característica esbranquiçada da fumaça. O processo de formação é o acréscimo do sufixo -eira à base branco, em analogia a formas como nevoeiro, aguaceiro, barulheira e cabeleira.

Com o uso do sufixo -dor temos mexedor (colher), sentador (cadeira) e cobridor (cobertor). Nas três palavras, o sufixo é preso a uma base verbal, criando o nome de um objeto que se usa para praticar a ação denotada pelo verbo, como ocorre nas palavras apagador, aspirador, espremedor, batedor e carregador. No caso de mexedor, ainda há uma derivação de grau, gerando a forma mexedorzinho em analogia a colherinha. 
Com o sufixo -ario foram criadas as palavras solário (dia) e lunário (noite). Nessas duas formações, o sufixo é preso a uma base nominal, apresentando a ideia de "relativo a", como ocorre também na formação dos vocábulos aquário, aviário, berçário, mobiliário e horário.

Há ainda a criação de um nome próprio (Latildo) para designar o cachorro de Marcelo. Aqui, o menino se vale da terminação -ildo que compõe muitos prenomes em português. Essa forma é de origem alemã - hild (masculino) e hilde (feminino) - e é empregada em nomes como, Hildemar, Hildegarda, Hildo, Hilda, Edenildo, Wanildo e Cazildete. Embora esse elemento possa ocorrer em posição final (Edenildo e Wanildo), inicial (Hildemar e Hildegarda), medial (Cazildete) e mesmo de forma absoluta (Hildo e Hilda $)^{\text {iv }}$, Viaro, Ferreira \& Guimarães Filho $(2014$, p. 98) detectam que o formativo -ildo tornou-se um novo sufixo na língua, sendo empregado, para além dos nomes próprios, em palavras como chatonildo, jumentildo, e espertildo.

Por fim, temos um caso de composição sintagmática com suco de vaca, significando leite. Esse é um processo de formação em que "os membros integrantes de um segmento frasal encontram-se numa íntima relação sintática, tanto morfológica quanto semanticamente, de forma a constituírem uma única unidade léxica" (ALVES, 2007, p. 50). Como nesses casos a nova unidade lexical sintagmática ainda está em processo de lexicalização, o hífen normalmente não é utilizado. Como explica Alves (2007, p. 51), em geral o uso do hífen "ratifica o sentimento de lexicalização em relação ao elemento classificado como composto".

A partir desse neologismo, Marcelo cria outro através do acréscimo do sufixo eira, gerando a palavra suco-da-vaqueira, em analogia à palavra leiteira. Aqui o sufixo tem o valor de objeto/instrumento, sendo acrescentado a uma base nominal, como em 
cabeceiro. Chama a atenção que, neste caso, o hífen foi utilizado para unir as partes do composto. Uma possível explicação para a variação no uso do hífen em suco de vaca e suco-da-vaqueira é a de que o processo de derivação a que se submeteu o segundo composto teria tornado mais evidente a lexicalização do sintagma, de modo que o hífen pode ser empregado.

\section{Considerações finais}

Como vimos, o texto literário, na medida em que leva ao limite as possibilidades da língua, torna-se uma importante fonte de dados para estudos linguísticos. Isso se nota de forma bastante evidente no caso das criações neológicas, especialmente em obras de literatura infantil.

Sendo assim, pudemos analisar as inovações lexicais na obra Marcelo, martelo, marmelo de Ruth Rocha, notando como as invenções de um personagem infantil nos ajudam a compreender melhor o funcionamento de processos de criação de palavras.

Ora seguindo os padrões linguísticos, ora burlando esses padrões, como no caso rompimento do bloqueio e da não observância da convencionalidade do signo, os neologismos presentes na obra em análise nos permitem ver certos mecanismos de criação lexical sendo usados em meio a um embate entre a norma linguística e o trabalho estético com a linguagem.

Embora os neologismos presentes em obras literárias como Marcelo, martelo, marmelo normalmente não tenham vida longa na língua, seu estudo não se torna menos pertinente, assim como o seu valor estilístico. Como observa Martins (1989, p. 111): 
[Os neologismos] evidenciam as potencialidades dos processos de renovação do léxico e dos elementos formadores (lexemas e morfemas), que são integrantes da língua. Ainda que novas palavras tenham existência efêmera, elas revelam um meio de o falante realizar o seu desejo de expressividade. Muitas delas são realmente de emprego restrito, e não poucas se limitam a uma ou outra ocorrência, da mesma forma que as metáforas que se criam para um único enunciado. Mas, pela sua novidade, causam um inegável efeito expressivo que não se pode menosprezar.

Portanto, a pesquisa neste campo é de grande valia não só para a melhor compreensão do texto literário em si, como também para o estudo da morfologia e da estilística léxica.

\section{Referências}

ALVES, leda M. Neologismo: criação lexical. São Paulo: Ática, 2007.

ARONOFF, Mark. Word formation in generative grammar. Cambridge: MIT Press, 1976. CAMARA JR., J. Mattoso. Contribuição à estilística portuguesa. Rio de Janeiro: Ao Livro Técnico, 1978.

Dicionário de linguística e gramática. Petrópolis, RJ: Vozes, 2004.

CAMPOS, Solange M. M. de. Malabarismos lexicais na literatura: os neologismos visitam a sala de aula. Anais do SIELP, v. 2, 2012, p. 1-14.

CORREIA, Margarita; ALMEIDA, Gladis M. de B. Neologia em português. São Paulo: Parábola, 2012.

COSTA, Marcos A. Estruturalismo. In: MARTELOTTA, M. E. (org.). Manual de linguística. São Paulo: Contexto, 2011. p. 113-126.

DUBOIS, Jean et al. Dicionário de linguística. São Paulo: Cultrix, 2006.

GUILBERT, Louis. Théorie du néologisme. In: Cahiers de l'Association internationale des études francaises, n. 25, 1973, p. 9-29. 
La créativité lexicale. Paris: Larousse, 1975.

LAJOLO, Marisa: ZILBERMAN, Regina. Literatura infantil brasileira: história e histórias. São Paulo: Ática, 1987.

MARTINS, Nilce Sant' Anna. Introdução à estilística: a expressividade na língua portuguesa. São Paulo: T. A. Queiroz, 1989.

O léxico de Guimarães Rosa. Edusp: São Paulo, 2001.

NASCENTES, Antenor. Dicionário etimológico da Língua Portuguesa. Rio de Janeiro: Francisco Alves, 1952.

ROCHA, Ruth. Marcelo, marmelo, martelo. São Paulo: Salamantra, 1976.

SAUSSURE, Ferdinand de. Curso de linguística geral. São Paulo: Cultrix, 2008.

SILVA, Maurício. Entreter e instruir: linguagem e literatura infantil. Revista Communitas, v. 1, n. 1, 2017, p.194-207.

VIARO, M. E., FERREIRA, M..J.; GUIMARÃES FILHO, Z. O. Derivação ou terminação: limites para a semântica, lexicologia e morfologia históricas. In: VIARO, M. E. (org.). Morfologia histórica. São Paulo: Cortez, 2014.

Recebido em 5 de fevereiro de 2019.

Aceite em 5 de abril de 2019.

\footnotetext{
'Dados retirados de Martins (2001).

ii Em todas as citações de obras escritas em língua estrangeira a tradução é nossa.

iii Como explica Dubois et al. (2006, p. 65), mesmo quando a relação entre o significado e o significante "muda de uma época para a outra, isso nunca se dá pela vontade de indivíduos isolados".

iv Dados retirados de Nascentes (1952).
} 